\title{
In Vitro Antifungal Susceptibility Testing of Tea Tree Oil (TTO) 5\% Compared with Nystatin against Candida sp. as Important Agent of Oral Candidiasis in HIV/AIDS Patients
}

\author{
Eva Lydiawati ${ }^{1}$, Muhammad Yulianto Listiawan', Dwi Murtiastutik ${ }^{1}$, Rahmadewi ${ }^{1}$, Cita \\ Rosita Sigit Prakoeswa ${ }^{1}$, Christina Avanti $^{2}$, Endang Wahyu Fitriani ${ }^{2}$, Erwin Astha \\ Triyono $^{3}$, Linda Astari ${ }^{1}$, Iskandar Zulkarnain ${ }^{1}$ \\ ${ }^{I}$ Department of Dermatology and Venereology, Faculty of Medicine, Universitas Airlangga/Dr. \\ Soetomo General Academic Teaching Hospital, Surabaya, Indonesia \\ ${ }^{2}$ Faculty of Pharmacy, Universitas Surabaya, Surabaya, Indonesia \\ ${ }^{3}$ Department of Internal Medicine, Faculty of Medicine, Universitas Airlangga/Dr. Soetomo General \\ Academic Teaching Hospital, Surabaya, Indonesia
}

\begin{abstract}
Background: Oral candidiasis is the most common clinical manifestation in a person infected with HIV which has been linked with the severity of the disease. Candida albicans responsible for most oral candidiasis. The increased resistance to the available antifungal drugs can reduce the efficacy of therapy. Therefore, it will be crucial to discover novel antifungal agents. One of them is tea tree oil (TTO) or Melaleuca alternifolia which has a potent antifungal effect to inhibit the growth of Candida $s p$. Purpose: To evaluate the antifungal susceptibility of TTO 5\% compared with nystatin against Candida $s p$. taken from HIV/AIDS patients. Methods: The study assessed the antifungal effect of TTO 5\% and nystatin against 33 isolates of Candida sp. that was isolated from the oral cavity of $30 \mathrm{HIV} / \mathrm{AIDS}$ patients in Dr. Soetomo General Academic Teaching Hospital Surabaya, Indonesia. Antifungal susceptibility was evaluated by the disc diffusion method. The diameter of the inhibition zone was determined as the result of this study. Result: The most strains found in this study was Candida albicans (84.8\%). The mean inhibition zone of nystatin against all strains was $23.24 \mathrm{~mm}$ whether it was $17.55 \mathrm{~mm}$ for TTO $5 \%$. The inhibition zone of both TTO 5\% and nystatin in Candida non-albicans were tended to be higher than in Candida albicans. It revealed that the inhibition zone of TTO 5\% significantly lower than nystatin $(\mathrm{P}=0.00 ; \mathrm{P}<0.05)$. Conclusion: Therefore, the antifungal susceptibility of nystatin was significantly higher than TTO 5\% against Candida albicans and non-albicans.
\end{abstract}

Keywords: tea tree oil, Melaleuca alternifolia, nystatin, antifungal susceptibility testing, oral candidiasis, HIV/AIDS.

Correspondence: Iskandar Zulkarnain, Department of Dermatology and Venereology, Faculty of Medicine, Universitas Airlangga/Dr. Soetomo General Academic Teaching Hospital, Jl. Mayjend Prof. Dr. Moestopo No. 6-8 Surabaya 60131, Indonesia. Telepon: 0818309859, email: zuljazid@yahoo.com.

\section{INTRODUCTION}

Oral candidiasis $(\mathrm{OC})$ is a kind of infection that is caused by Candida sp. in oral mucous membrane. It is the most common clinical manifestation in HIV/AIDS patients. It has several manifestations that can be acute, subacute, and chronic infections. ${ }^{1,2}$ Most of patients with HIV/AIDS have experienced OC in the course of its illness and found in patient with CD4 T-cell count around and $<200 / \mathrm{mm}^{3}$ with high viral load number. ${ }^{2-4}$ In these population, Candida albicans (C. albicans) is the species that is commonly found for most of infections. $^{5}$ The most common etiology of OC in HIV/AIDS patients are C. albicans in Surabaya, Indonesia in around $54 \%$ of the subjects ${ }^{2}$ and also in Malang, Indonesia. ${ }^{6}$ While there was also some nonalbicans species that cause this infection, like $C$. glabrata, C. krusei, $C$. parapsilosis, and $C$. tropicalis. $^{2,5}$

The main treatment of OC is by using antifungal treatment that can be applied orally or topically on the oral mucous membrane. ${ }^{5,7}$ The mostly found topical treatment is nystatin oral drop that is also the primary treatment of OC in Dr. Soetomo General Academic Teaching Hospital Surabaya, Indonesia. ${ }^{8}$ The study in Iran showed that there was $4 \%$ subjects in that study that was resistance to nystatin, ${ }^{9}$ although in the low number of nystatin resistance. Therefore, it become very important for the discovery of new antifungal agents in order to widen the spectrum of activity against Candida and increase the effectiveness of the OC treatment.

There are also several natural products have shown its efficacy to be the candidate of alternative therapy for OC. One of those natural products is 
Melaleuca alternifolia (M. alternifolia) or commonly known as tea tree oil (TTO). It shown potential antifungal effect against Candida $s p .{ }^{10}$ It showed that the active component, terpinen-4-ol, controlled the growth of $C$. albicans in vitro. ${ }^{10,11}$ The minimum inhibitory concentration (MIC) was 4.84-25.33\% with minimum fungicidal concentration (MFC) was around 25.33-32.00\%. MIC showed the minimal concentration of some product can inhibit the growth of Candida sp. ${ }^{5}$ Based on the MIC, we choose the $5 \%$ concentration to be analysed in this study in the gel emulsion (emulgel) base products.

The objective of this study was to evaluate the antifungal susceptibility of TTO 5\% compared with nystatin against Candida $s p$. taken from HIV/AIDS patients in order to subsidize new therapeutic strategies for this infection.

\section{METHODS}

Subject in this research were HIV/AIDS patients at Dr. Soetomo General Academic Teaching Hospital Surabaya, Indonesia. Inclusion criteria of subject were patient diagnosed with HIV/AIDS that have been diagnosed of $\mathrm{OC}$ and had several clinical manifestations of OC like acute pseudo membranous $\mathrm{OC}$, acute or chronic atrophic OC, perleche, and hyperplastic OC. Those diagnoses confirmed by positive result of potassium hydroxide $(\mathrm{KOH})$ examination. They were more than or equal to 21 -yearold and willing to take part in the study. Criteria exclusion of this study was the HIV/AIDS patient with OC that was treated with antifungal treatment, systemically or topically, between 2 weeks prior the study. Subject who were willing to take part in this study get an explanation regarding the research and assign the informed consent form prepared by the researcher.

This laboratory experimental study was be held from Desember 2019 to February 2020. This study was conducted in UPIPI Dr. Soetomo General Academic Teaching Hospital, Surabaya, Indonesia and Surabaya Health Laboratory, Indonesia. The number of subjects were $30 \mathrm{HIV} / \mathrm{AIDS}$ patients who went through the identification process.

The procedure of this study began with the specimen taken from the oral tissue swabs then was implanted into the CHROMagar Candida media. The culture was grown for about 36-48 hours and followed by the species identification tests. The species that was found in this study were 33 strains consists of $C$. albicans and non-albicans. The antifungal susceptibility testing was performed by using disc diffusion method on Mueller Hinton agar with 2\% glucose and methylene blue. Candida species isolates were implanted in the agar, then paper discs containing nystatin and TTO 5\% were placed on the media. It was observed in 24-48 hours and the resistance zone was measured with the calipers. The resistance zone then was compared between TTO 5\% and nystatin. The results were documented, which then be presented and evaluated in the form of tables and graphs. The data then were analyzed using SPSS Statistics 26 version application. This research has obtained ethical approval from the Ethics Committee of Dr. Soetomo General Academic Teaching Hospital Surabaya (1651/KEPK/XI/2019).

\section{RESULT}

We analyzed 30 subjects that has characteristic stated on the Table 1. There were 33 Candida strains collected from oropharyngeal mucous membrane of HIV/AIDS patients, $28(84.80 \%)$ of them was $C$. albicans. The non-albicans was also found in 5 $(15.20 \%)$ strains, consisted of C. glabrata $(9.10 \%)$ and C. tropicalis $(6.10 \%)$ like we can observed on Figure 1. There was more than one species of Candida that was found on 2 patients.

All the strains of Candida showed the inhibition zone in nystatin. The mean diameter of the nystatin inhibition zone of 33 strains was $23.24 \mathrm{~mm}$, while the nystatin inhibition zone of C. albicans was $23.25 \mathrm{~mm}$ and non-albicans was $23.20 \mathrm{~mm}$. We used the sensitivity criteria according to Clinical and Laboratory Standards Institutes (CLSI) for nystatin ${ }^{12}$ (Table 2). According to the criteria we observed that all the strains were sensitive to nystatin and no strains that were resistant to this drug.

The mean diameter of the TTO 5\% inhibition zone off 33 strains was $17.55 \mathrm{~mm}$, while the TTO 5\% inhibition zone of C. albicans was $17.43 \mathrm{~mm}$ and nonalbicans was $18.20 \mathrm{~mm}$. There was no CLSI criteria for TTO, so we could not conclude the sensitivity of this drug. The antifungal susceptibility that was comparable between TTO 5\% and nystatin was the inhibition zone diameter ( $\mathrm{mm}$ ).

The mean diameter of inhibition zone of nystatin was greater than TTO 5\%, which was $23.24 \mathrm{~mm}$ compared to $17.55 \mathrm{~mm}$ (Figure 2). The non-parametric statistical result showed that there was significance difference between the diameter of inhibition zone between TTO 5\% and nystatin ( $\mathrm{P}=0.00$; sig. $<0.05)$. The TTO 5\% inhibition zone of C. albicans and nonalbicans were also smaller than nystatin. The inhibition zone of both TTO 5\% and nystatin in Candida nonalbicans were tend to be higher than in Candida albicans. It revealed us that the inhibition zone of TTO $5 \%$ significantly lower than nystatin. So that, we 
observed that the fungistatic effect of TTO $5 \%$ was

lower compared to nystatin in this study.

Table 1. Demographic Data of Patient

\begin{tabular}{|c|c|c|c|c|c|}
\hline \multirow{2}{*}{ No } & \multicolumn{4}{|c|}{ Basic Data } & \multirow[b]{2}{*}{$\mathbf{p}$} \\
\hline & Category & Group & $\mathbf{N}$ & $\%$ & \\
\hline \multirow{2}{*}{1.} & \multirow{2}{*}{ Sex } & Man & 26 & 86.70 & \multirow{2}{*}{0.61} \\
\hline & & Woman & 4 & 13.30 & \\
\hline \multirow{5}{*}{2.} & \multirow{5}{*}{ Age } & Late teens $(18-25$ year $)$ & 1 & 3.80 & \multirow{5}{*}{0.64} \\
\hline & & Early adult ( $26-35$ year $)$ & 12 & 46.20 & \\
\hline & & Late adult (46 - 55 year) & 8 & 30.80 & \\
\hline & & Early senior adult ( $46-55$ year) & 8 & 30.80 & \\
\hline & & Late senior adult $(56-65$ year $)$ & 1 & 3.80 & \\
\hline \multirow{4}{*}{3.} & \multirow{4}{*}{ Education } & Graduated from elementary school & 3 & 11.50 & \multirow{4}{*}{0.05} \\
\hline & & Graduated from junior high school & 1 & 3.80 & \\
\hline & & Graduated from high school & 22 & 84.60 & \\
\hline & & Graduated from diplome/S1 & 4 & 15.40 & \\
\hline \multirow{7}{*}{4.} & \multirow{7}{*}{ Occupation } & Unemployed & 10 & 33.30 & \multirow{7}{*}{0.19} \\
\hline & & Civil servants & 1 & 3.30 & \\
\hline & & Private employees & 11 & 36.70 & \\
\hline & & Student & 1 & 3.30 & \\
\hline & & Housewives & 2 & 6.70 & \\
\hline & & Driver & 3 & 10.00 & \\
\hline & & Trader & 2 & 6.70 & \\
\hline
\end{tabular}

\section{Candida Strains}

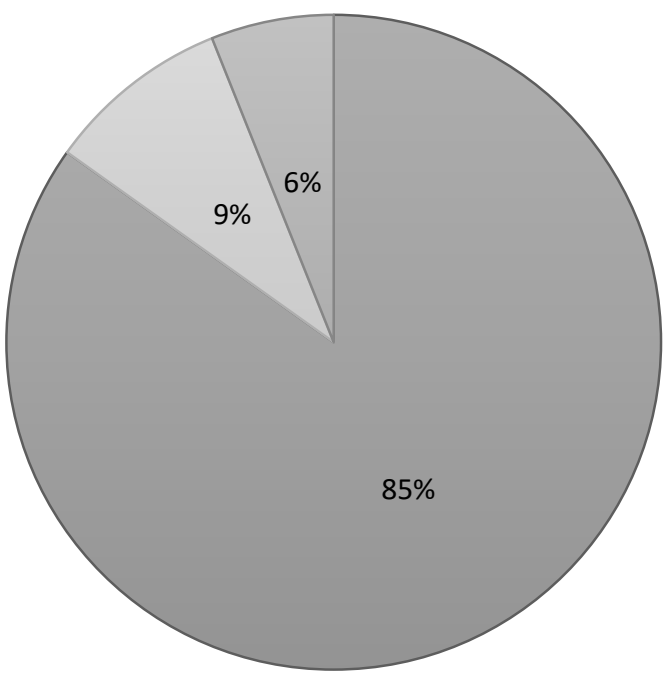

$\square$ Candida albicans $\square$ Candida glabrata $\square$ Candida tropicalis

Figure 1. The Candida strains found in this study.

Table 2. Nystatin inhibition zone for Candida $s p .{ }^{12}$

\begin{tabular}{ccccc}
\hline \multirow{2}{*}{ Drug } & \multirow{2}{*}{ Potention } & \multicolumn{3}{c}{ Inhibition Zone Diameter $(\mathrm{mm})$} \\
\cline { 3 - 4 } Nystatin & $50 \mu \mathrm{g} /$ disc & Sensitive & Intermediate & Resistant \\
\hline
\end{tabular}




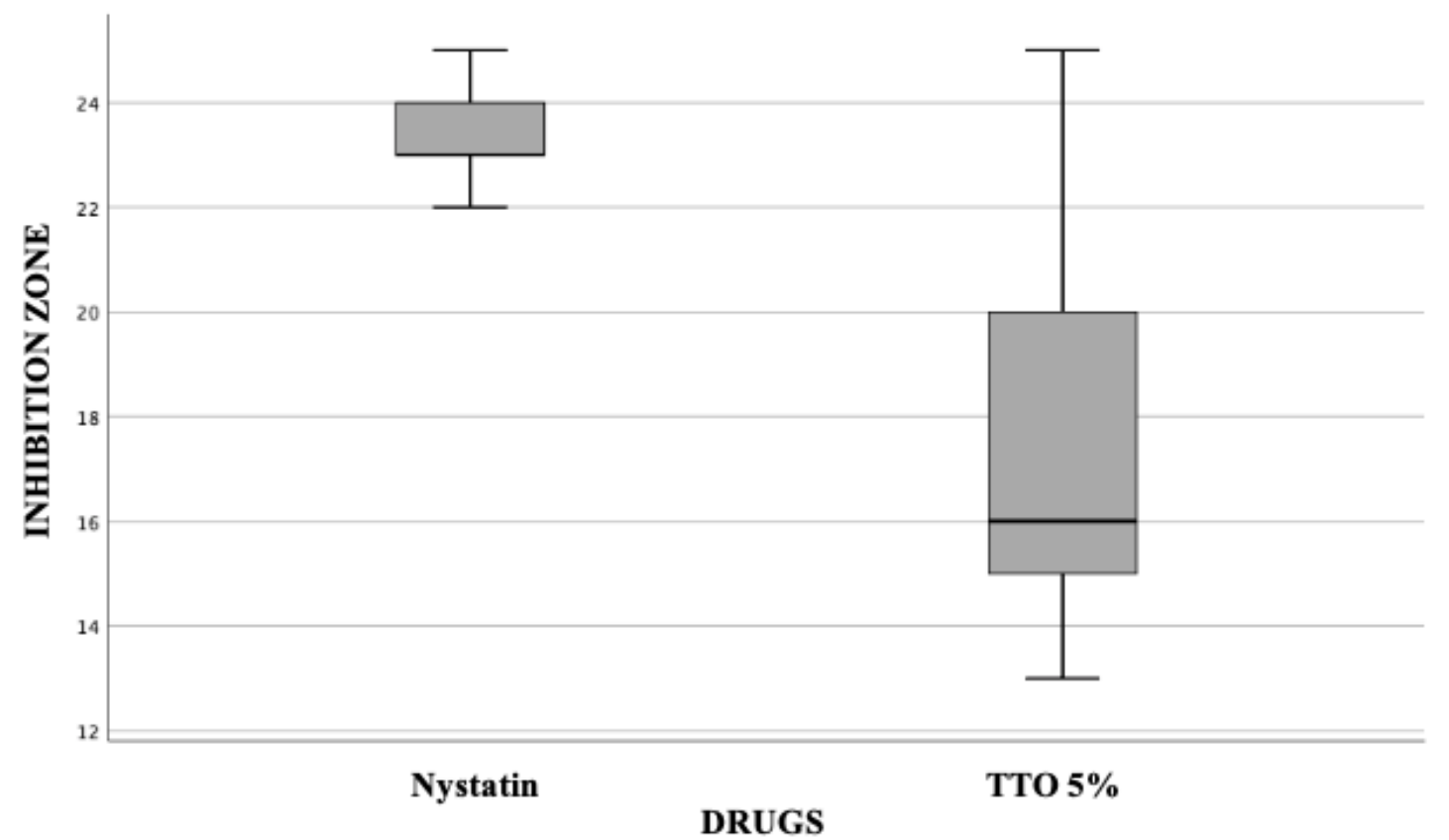

Figure 2. The diameter of inhibition zone comparation between TTO 5\% and nystatin.

\section{DISCUSSION}

Oral candidiasis (OC) is an opportunistic fungal infection commonly found in HIV-positive patients, that is caused by Candida sp. ${ }^{5}$ Candida albicans had shown as a widespread species in HIV/AIDS patients. ${ }^{7,9}$ The result in this study show that although there were some non-albicans strains, C. albicans remains the most prevalent species that is caused OC in the subjects.

Nystatin proved to be sensitive to all species found in this study. The sensitivity also proved in other research held in Indonesia and other country. $2,6,12,13$ Moges et al. proved that $96.8 \%$ Candida $s p$. in their study in Ethiopia (2013) were sensitive to nystatin. ${ }^{14}$ But, there were also research that showed that some species were resistant to nystatin, like in the study held by Dar et al. in India (2015) stated that $61.1 \%$ subjects were sensitive, $36.1 \%$ intermediate, and $2,8 \%$ resistant to nystatin. ${ }^{15}$ This could be caused by the changes in sterol composition in the Candida's cell membrane that could decrease the affinity of the this drug to the membrane itself. ${ }^{7,16}$

TTO 5\% exhibited the antifungal effect against Candida $s p$. in this study. This effect was proved by the TTO inhibition formed in the media with the diameter of $17.55 \mathrm{~mm}$ in all species. Hammer et al. established the study that proved that TTO and its component increased the membrane cell permeability. This could inhibit the growth of Candida $s p .{ }^{17}$ TTO could also produce membrane lipid bilayers like structure that change the component to make the membrane intact. This changes lead to inhibition of growth of Candida. ${ }^{17,18}$
The mean diameter of TTO inhibition zone of Candida albicans were slightly shorter than the nonalbicans species. It means that the antifungal susceptibility of TTO against $C$. non-albicans was better than those in $C$. albicans. This was similar that was found by Oro et al (2015). Those study proved that the MIC of $C$. albicans was higher than $C$. nonalbicans. MIC of $C$. albicans and non-albicans was $20.03 \%$ and $4.84 \%$ respectively. TTO need higher concentration to inhibit the growth of C. albicans. ${ }^{5}$ This could be caused by the ability of $C$. albicans to form germination tube and biofilm, so that it could protect the fungi from the environmental changes caused by TTO. ${ }^{19}$ The small sample of non-albicans species might be affect those result too.

The diameter of nystatin inhibition zone was significantly larger than TTO 5\%. This could be caused by the mechanism of those drugs that were slightly different. Nystatin found to bind ergosterol as the main component of fungal cell membrane. It produced the pore-like structure and lead to the leakage of the plasma lead to fungal cell death. ${ }^{20}$ This was different with TTO mechanism, in which TTO also altered the permeability of fungal cell membrane, but it could not produce pore-like structure like it was happened in nystatin. $^{21}$ TTO had fungistatic properties, but the fungicidal effect was only found in the higher concentration. ${ }^{5,21}$

This study used TTO with $5 \%$ in concentration. This concentration was chosen because of the reason to use the minimal concentration that was effective with low toxicity risk, in order to prepare the drug to be used by human in the future. This was according to the MIC 
proved by Oro et al with the MIC TTO in 4.84$25.33 \% .{ }^{5}$ TTO could inhibit the respiration process of Candida sp. in dose-dependent manner. The higher dose that have been used, the better inhibition of the fungal activity. ${ }^{19}$ The toxicity effect of TTO like skin and mucous membrane irritation, allergic contact dermatitis, erythema or bullous reaction, and hypersensitivity could be found in the higher dose or concentration. ${ }^{22,23}$ The use of TTO with concentration up to $20 \%$ was thought to be safe and had no serious side effect. ${ }^{23}$

In conclusion, based on the result of this study, nystatin and TTO showed antifungal effect against Candida $s p$. isolated from HIV/AIDS patients. Therefore, the antifungal susceptibility of nystatin was significantly higher that TTO 5\% against Candida albicans and non-albicans. Moreover, the TTO in higher concentration (TTO 10\%) needs further investigation to be compared with TTO $5 \%$ to established the optimal concentration of antifungal treatment of $\mathrm{CO}$ in HIV/AIDS patient.

\section{References}

1. Kundu R V., Garg A. Yeast Infections: Candidiasis, Tinea (Pityriasis) Versicolor, and Malassezia (Pityrosporum) Folliculitis. In: Goldsmith LA, Katz SI, Gilchrest BA, Paller AS, Leffel DJ, Wolff K, editors. Fitzpatrick's dermatology in general medicine. 8th ed. New York: McG. 2012. p. 2298-301.

2. Murtiastutik D, Maharani CS, Rahmadewi R. Profile of Candida Resistancy to Fluconazole in Male Patient with Oral Candidiasis and HIV/AIDS. J AIDS Clin Res 2019; 10(1): 1-6.

3. Berberi A, Noujeim Z, Aoun G. Epidemiology of Oropharyngeal Candidiasis in Human Immunodeficiency Virus/Acquired Immune Deficiency Syndrome Patients and CD4 + Counts. J Int Oral Heal 2015; 7(3): 20-3.

4. Nugraha AP, Ernawati DS, Parmadiati AE, Soebadi B, Triyono EA, Prasetyo RA, et al. Prevalence of Candida Species in Oral Candidiasis and Correlation with CD4+ Count in HIV/AIDS Patients at Surabaya, Indonesia. J Int Dent Med Red 2018; 11(1): 81-5.

5. Oro D, Heissler A, Rossi EM, Scapin D, da Silva Malheiros P, Boff E. Antifungal Activity of Natural Compounds Against Candida Species Isolated from HIV-Positive Patients. Asian Pac J Trop Biomed 2015; 5(9): 781-4.

6. Reza NR, Sugiman T, Basuki S. Uji Kepekaan In Vitro Flukonazol terhadap Spesies Candida penyebab Kandidiasis Oral Pada Pasien HIV/AIDS dengan Vitek II (In Vitro Susceptibilty Test of
Fluconazole to Candida spp in Patients with Oropharyngeal Candidiasis and HIV / AIDS with Vitek II). BIKKK 2017; 29(3): 234-42.

7. de Oliveira Santos GC, Vasconcelos CC, Lopes AJO, de Sousa Cartagenes M do S, Filho AKDB, do Nascimento FRF, et al. Candida Infections and Therapeutic Strategies: Mechanisms of Action for Traditional and Alternative Agents. Front Microbiol 2018; 9(1351): 1-23.

8. RSUD Dr. Soetomo. Panduan Praktik Klinis (PPK) Kandidiasis Oral. 2014. p. 1-29.

9. Mohamadi J, Motaghi M, Panahi J, Havasian MR, Delpisheh A, Azizian $M$, et al. Anti-Fungal Resistance in Candida Isolated from Oral and Diaper Rash Candidiasis in Neonates. Bioinformation 2014; 10(11): 8-11.

10. Catalán A, Pacheco JG, Martínez A, Mondaca MA. In vitro and In Vivo Activity of Melaleuca alternifolia Mixed with Tissue Donditioner on Candida albicans. Oral Surg Oral Med Oral Pathol Oral Radiol Endod 2008; 105: 327-32.

11. Mondello F, Bernardis F De, Girolamo A, Cassone A, Salvatore G. In Vivo Activity of Terpinen-4-ol, The Main Bioactive Component of Melaleuca alternifolia Cheel (tea tree) Oil against AzoleSusceptible and -Resistant Human Pathogenic Candida species. BMC Infect Dis 2006; 6(158): 19.

12. Djajusman SK, Tedjosasongko U, Irmawati I. Daya Hambat Xylitol dan Nistation terhadap Pertumbuhan Candida albicans (in vitro) (Inhibition Effect of Xylitol and Nistatin Combination on Candida albicans Growth (in vitro)). Dent J 2014 (Maj. Ked. Gigi); 47(3): 1647.

13. Kumar DA, Muralidhar S, Banerjee U, Basir SF, Mathur P, Khan LA. Diversity and Antifungal Resistance Patterns of Prevalent Opportunistic Pathogenic Yeasts Colonizing the Oral Cavities of Asymptomatic Human Immunodeficiency Virus Infected Individuals, and their Relation to CD4 + Counts. Indian J Sex Transm Dis AIDS 2015; 36(1): 53-8.

14. Moges B, Bitew A, Shewaamare A. Spectrum and the In Vitro Antifungal Susceptibility Pattern of Yeast Isolates in Ethiopian HIV Patients with Oropharyngeal Candidiasis. Int J Microb 2016; 3037817: 1-8.

15. Dar MS, Sreedar G, Shukla A, Gupta P, Rehan AD, George J. An In Vitro Study of Antifungal Drug Susceptibility of Candida Species Isolated from Human Immunodeficiency Virus Seropositive and Human Immunodeficiency Virus Seronegative Individuals in Lucknow Population Uttar Pradesh. 
J Oral Maxillofac Pathol 2015; 19(2): 205-11.

16. Fothergill AW, Sutton DA, McCarthy DI, Wiederhold NP. The Impact of New Antifungal Breakpoints on Antifungal Resistance in Candida. J Clin Mucrobiol 2014; 1: 1-18.

17. Hammer KA, Carson CF, Riley T V. Antifungal Effects of Melaleuca alternifolia (Tea Tree) Oil and Its Components on Candida albicans, Candida glabrata and Saccharomyces cerevisiae. J Antimicrob Chemother 2004; 53(6): 1081-5.

18. Pereira TS, de SantAnna JR, Silva EL, Pinheiro AL, de Castro-prado MAA. In Vitro Genotoxicity of Melaleuca alternifolia Essential Oil in Human Lymphocytes. J Ethnopharmacol [Internet] 2014; 151: 852-7.

19. Mertas A, Garbusinska A, Szliszka E, Jureczko A, Kowalska M, Król W. The Influence of Tea Tree Oil (Melaleuca alternifolia) on Fluconazole
Activity against Fluconazole-Resistant Candida albicans Strains. Biomed Res Int 2015; 2015: 1-9.

20. Ahronowitz I, Leslie K. Yeast Infections. In: Kang, S., Amagai, M., Bruckner, A.L., Enk, A.H., Margolis, D.J., McMichael, A.J., Orringers, J.S., editors. Fitzpatrick's dermatology. 9th ed. New York: McGraw Hill. 2019; 2952-63.

21. Carson CF, Hammer KA, Riley T V. Melaleuca alternifolia (Tea Tree) Oil: a Review of Antimicrobial and Other Medicinal Properties. Clin Microbiol Rev 2006; 19(1): 50-62.

22. de Groot AC, Schmidt E. Tea Tree Oil: Contact Allergy and Chemical Composition. Contact Dermatitis 2016; 75: 129-43.

23. Pazyar N, Yaghoobi R, Bagherani N, Kazerouni A. A Review of Applications of Tea Tree Oil in Dermatology. Int J Dermatol 2013; 52: 784-90. 